\title{
Taking monism seriously
}

\author{
David M. Cornell ${ }^{1}$
}

Published online: 7 January 2016

(C) The Author(s) 2016. This article is published with open access at Springerlink.com

\begin{abstract}
Monism is the view that there is only a single material object in existence: the world. According to this view, therefore, the ordinary objects of common sense-cats and hats, cars and stars, and so on-do not actually exist; there is only the world. Because of this, monism is routinely dismissed in the contemporary literature as being absurd and obviously false. It is simply obvious that there is a plurality of material things, thus it is simply obvious that monism is false, or so the argument goes. I call this the common sense argument against monism and in this paper I offer a response. I argue that providing the monist can make his view consistent with the appearance that there is a multiplicity of material things, then it is not rationally acceptable to reject monism solely on the basis of that appearance. Through an appeal to a particular type of property-distributional properties-I sketch out a plausible story of how monism is perfectly consistent with the appearance of plurality, and thus nullify the common sense argument. There may be any number of arguments that serve to undermine monism, but the common sense argument is not one of them. Monism deserves to be taken more seriously than that.
\end{abstract}

Keywords Monism · Mereology $\cdot$ Common sense $\cdot$ Properties · Distributional properties

David M. Cornell

david_cornel12000@hotmail.com

1 Department of History, Politics, and Philosophy, Manchester Metropolitan University, Geoffrey Manton Building, Rosamund Street West, Manchester M15 6LL, UK 


\section{Introduction}

The term 'monism', as I will be employing it here, refers to the view that there is only a single material object in existence: the world itself. ${ }^{1}$ According to this view, the world is mereologically simple, it has no proper parts. One significant consequence of this is that if monism is true, then the vast number of material objects that are ordinarily recognised by common sense do not, in fact, exist. For the monist, there are no tables or chairs, no doughnuts or pillar boxes, not even any human beings. Because of this, monism is routinely and summarily dismissed as being obviously false. So absurd are its consequences, and so obvious is its falsity, that monism is dismissed out of hand as being little more than some crack-pot relic of Eleatic history. In this paper, I will argue that this rejection of monism is far too quick. The conflict between monism and common sense can be easily explained away, and as such, does not provide sufficient grounds on which the theory can be rejected. I should make it clear that in what follows I will not be trying to argue that monism is true. That is a different and substantial project in its own right, and one that would go way beyond the scope of a paper such as this. ${ }^{2}$ My aim is more modest: to show that the most common reason for rejecting monism (i.e. the objection that it is obviously false) is unjustified and unconvincing. Monism deserves to be taken seriously.

\section{The common sense objection}

To say that monism is unpopular among contemporary philosophers would be somewhat of an understatement. Of those philosophers who have taken the time to consider it at all, the vast majority deride it as being not only false, but as obviously, and even absurdly false. ${ }^{3}$ Jonathan Barnes, for instance, says of monism that it is "at best absurd and at worst unintelligible" (1979: 1). More recently, Jonathan Schaffer claimed that "Monism is a crazy view" , and went on to say elsewhere, "Of course whole and part both exist. There is the world, you and I, and all of our various parts. Who could deny it?" (2007:189). Overall, the general antipathy toward monism has been perfectly summed up by Michael Rea:

\footnotetext{
1 It has become quite common in contemporary literature for this view to be called 'existence monism'. This term was coined by Schaffer (2007) in order to distinguish it from his own view, 'priority monism', according to which there are lots of material objects in existence, but only one-the world-is fundamental. Since I will not be concerned with priority monism in this paper, I will stick with the simpler term, 'monism'.

${ }^{2}$ I do, however, think that monism is a plausible thesis, and that compelling arguments can be offered in its defence. See, for instance, Horgan and Potrc (2000, 2008) or Rea (2001).

3 This is only the case in the last 100 years or so, however. Monism has a long and rich history spanning right back to the early Greeks, most notably, Parmenides.

4 Schaffer (2010), 324. Schaffer is referring to Existence Monism, of course, as opposed to his own view, Priority Monism.
} 
The problem is not just that Eleatic monism seems to be false. Rather, the problem is that it seems to be so incredibly wide of the mark, so vastly out of touch with the truth, that it is hard to see what sorts of considerations could have led someone even to take it seriously, much less embrace it. (2001: 129). ${ }^{5}$

This pervasive distaste for monism is indubitably driven by an appeal to common sense and intuition. That is, the reason why so many philosophers find monism so unpalatable is plainly and simply that it conflicts with a central tenet of common sense, namely, that there is a multiplicity of material objects. To leave the reader in no doubt that this $i s$ the driving force behind the common aversion to monism, I invite you to consider a few more relevant quotations. First, from Bertrand Russell: "I share the common-sense belief that there are many separate things" (1918: 2). Secondly, from William Hocking: "plain observation shows the world not as one, but as many things of many kinds" (1929: 371). Finally, and a little more recently, from Hoffman and Rosenkrantz: "Monism [...] is inconsistent with something that appears to be an evident datum of experience, namely, that there is a plurality of things. We shall assume that a plurality of material things exists, and hence that monism is false." (1997: 78)

It may appear that I am labouring the point somewhat here, but that is not my intention. Rather, I am merely trying to impress upon the reader both the level of antipathy with which monism is subjected to in the contemporary literature, and indeed the source of this antipathy. Monism is barely given a chance. But, with very few exceptions, these naysayers do not pretend to argue against monism in any substantive fashion; instead, they simply claim it to be obviously false. ${ }^{6}$ It is obviously false, they say, because it is obvious that there are many things. This is what I shall call the common sense objection. In what follows, I will show that the common sense objection is so easily overcome that it provides no real grounds for rejecting monism at all.

\section{Overcoming the common sense objection}

There is a fairly straightforward strategy which the monist can employ in order to overcome the common sense objection. Indeed it is a strategy which could be employed in general, by the proponent of any philosophical theory which conflicts with some purported truism of common sense. The general strategy can be simply fleshed out as follows. If some philosophical theory, $T$, entails the negation of some common sense proposition, $p$, then in order to dissolve the resulting conflict with common sense, all that is required of $T$ 's proponent is some kind of explanation as to why it seems as though $p$ is true, when it is in fact false. If an explanation of this

\footnotetext{
5 Rea (2001), 129. Rea uses the term 'Eleatic' to reflect the theory's roots in the ancient Greeks of Elea, most notably Parmenides. I should also make clear that Rea does not take this dismissive view of monism himself, but is merely summarising the reception it commonly receives.

${ }^{6}$ Sider (2007) is the notable exception here, having provided a number of different arguments against monism. See Cornell (2013) for a reply. Goff (2012) has also provided an argument against monism.
} 
sort can be provided, then one is no longer rationally entitled to reject $T$ solely on the grounds that it conflicts with $p$. To do so would be unreasonable and obtuse, or so I claim. The presence of such an explanation does not mean, of course, that one must now accept that $T$ is true-there may be a whole host of independent reasons still to reject it. But what it does mean is that one cannot rationally reject $T$ solely on the grounds that it conflicts with common sense; one is required to take it a little more seriously than that. In the present case, therefore, for the monist to overcome the common sense objection, she must provide some kind of explanation as to why it seems as though there is a plurality of concrete objects, when in fact there is only one.

In Sect. 5 I will provide an explanation to do exactly that, but first it should be worthwhile to provide a little support for the proposed strategy. After all, the reader may not be convinced that such a strategy should be considered sufficient to overcome the common sense objection. ${ }^{7}$ To illustrate why I think that the strategy should be accepted, I ask you to consider the following thought experiment. Suppose you were to travel back in time to an age at which science had yet to uncover any of the facts about planetary motion. For the people at that time, we can suppose that it was universally accepted that the Earth was perfectly stationary. We can even suppose that this belief was so entrenched that it had never even been questioned; the thought that the Earth was not stationary had never been entertained. ${ }^{8}$ Now I don't have a specific or technical definition in mind for that body of knowledge we call common sense, but I will assume that under any reasonable definition, for the people in the scenario described, the proposition that the Earth is stationary would certainly qualify as a common sense truism. After all, it would appear to those people as an evident datum of experience that the Earth was not in motion, just as it would appear to them that grass is green, or that night follows day.

Now suppose that you were to gather some of these people together and announce to them that, contrary to their beliefs, the Earth was not stationary, but was in fact continuously revolving upon its axis, as well as hurtling through space in an orbit around the Sun at an average speed in excess of sixty-five-thousand miles per hour. These people, it is reasonable to expect, would simply not believe you. Indeed, it is more than likely they would brand you as crazy. And justifiably so! It would seem so obvious to these people that they were not travelling through space at such high speeds as to make your claim seem clearly and evidently absurd. "Your claim is obviously false," one can imagine the retort, "just look around you; everything is still and calm. If we were moving at that speed we would be blown off our feet!" Such a response would be entirely justified, it seems to me, for your claim, when so baldly asserted, would seem so obviously contrary to the facts; it would appear to be in direct conflict with the phenomenological data.

\footnotetext{
7 This will particularly be case for readers of a Moorean persuasion. Needless to say, this paper is written from a robustly anti-Moorean standpoint.

${ }^{8} \mathrm{I}$ am presuming that there was a time when this was the case. But even if people have never thought this, at any time, it does not affect the experiment. One merely needs to imagine that there was such a time, and that there were such a people.
} 
But now suppose that you went on to explain to these people some rudimentary facts about planetary motion and about the Earth's atmosphere. You could explain how it is that your story about the motion of the Earth fits in with the apparent motion of the stars in the night sky. You could explain how the revolution of the Earth upon its axis explains the regular transition from night to day, and how the orbital transit of the Earth around the Sun explains the regular and cyclical changing of the seasons. More crucially, you could explain that because the Earth has an atmosphere, and that this atmosphere moves with the Earth, why it is that we don't get blown off our feet by a sixty-five-thousand mile an hour wind, despite the great speed with which we are actually travelling. With the right amount of additional explanatory information, your initial assertion that the Earth is hurtling through space at high speed should no longer seem so contrary to the phenomenological data. Indeed, it should now be seen as being perfectly consistent with the data-for if your story were true, the data would be exactly the same.

Now here is the point. Whether these ancient people would, or should, be convinced by your story is entirely up for debate. But what is clear, or at least, what should be clear, is that if they were at all rational then they could not simply and flatly deny your assertion in the same way they had done before. They could not simply say, "you're wrong, just look around you, it is obvious that we are stationary". That would be an objectionably obtuse response, since as your explanation made clear, your story about the Earth being in motion is just as compatible with the phenomenological data as their story about the Earth being still. For if your story were true, the phenomenological data would be exactly the same: it would still seem as though the earth were standing still. Thus the initial objection (of course we're not moving!) would have lost all of its bite, and providing the objectors had understood your explanation, it would be entirely unreasonable for them to keep faith in it.

The initial objection offered by the ancient people in the thought experiment is clearly analogous to the common sense objection against monism. For in both cases, a certain claim is objected to on the grounds that it conflicts with some common sense fact that is taken to be evident from the phenomenological data. But as the thought experiment shows, if the proponent of the contested claim has some explanation that makes his claim consistent with the data, then one cannot, or should not, continue to object to the claim solely on the grounds that it conflicts with those data. For if the explanation successfully achieves its aim, then there will not be any such conflict. Let us call an explanation of this type a sufficient alternative explanation (SAE). The notion of an SAE is the key to the strategy I am proposing. In the general case, then, the strategy is as follows. If some theory, $T$, entails the negation of some proposition of common sense, $p$, then in order to overcome the common sense objection (i.e. the objection that states, $p$ therefore $\sim T$ ), all that is required of $T$ 's proponent is an SAE that explains why it seems as though $p$ is true when it is in fact false. If such an explanation is forthcoming, one is no longer rationally entitled to object to $T$ solely on the grounds that it conflicts with $p$. The SAE nullifies the common sense objection. In the present case, therefore, the monist has to provide an SAE for the common sense proposition that there is a plurality of material things. If the monist can provide an explanation of why it seems as though 
this proposition is true when it is actually false, then she will have successfully nullified the common sense objection. ${ }^{9}$

This strategy is not entirely new. Peter van Inwagen (1990) employed a very similar strategy in his Material Beings. van Inwagen proposed a theory stating that the only material objects in existence were either simples (i.e. objects with no proper parts) or living organisms. A direct consequence of this theory is that there are no inanimate composite objects; no chairs or tables, no rocks or planets, no planes, trains or automobiles. van Inwagen called this initially startling consequence of his theory, "the denial" (1990: 1). The denial flies in the face of common sense; for it is surely obvious that there are chairs and tables, and rocks and planets, etc. It is simply absurd to suggest that there are none of these things, for such a claim is so evidently at odds with the phenomenological facts. Of course, van Inwagen was well aware of this apparent absurdity. But he was untroubled by it, because he had his own SAE. That is, he provided an explanation of why it seems as though there are inanimate composite objects when in fact there are none. His explanation was that whilst there are no chairs, for instance, there are simples arranged chair-wise; whilst there are no rocks, there are simples arranged rock-wise; and so on and so forth. In general, the appearance of composite objects was to be explained by the existence of microscopic simples arranged composite object-wise.

In light of van Inwagen's SAE, his theory becomes much harder to refute. What is for certain is that one can't simply refute it by pointing to the phenomenological data. One can't say, "your theory is obviously false, because there is a chair, and there is a rock" etc. To give such a response would prove only that you haven't understood van Inwagen's SAE. It would not prove that there are chairs and rocks. It would be no better than Dr Johnson's alleged stone-kicking refutation of Berkelean Idealism. Of course, this does not mean that you have to accept van Inwagen's theory as true. What it does mean, however, is that the common sense objection alone (i.e. of course there are chairs-there is one!) does not provide sufficient reason to reject it. One would have to work a bit harder than that, and object to it on alternative grounds.

\footnotetext{
${ }^{9}$ I think it is worthwhile to briefly mention here the position of Horgan and Potrc (2000, 2008), who are the only contemporary philosophers I am aware of who actually endorse existence monism in print. Horgan and Potrc employ a somewhat unusual semantic framework according to which truth, in most contexts at least, is a matter of indirect correspondence with reality. Without going into the complex intricacies of their view, this means that they can accept sentences as being strictly and literally true, even if the objects which those sentences purport to refer to do not in fact exist. For example, the sentence, "the cat sat on the mat", can on their view be strictly and literally true even though there are no such things as cats or mats. It should be noted, therefore, that Horgan and Potrc's view already comes equipped with a response to the common sense objection, albeit a markedly different response to my own. In fact, Horgan and Potrc would reject the claim that their monistic view conflicts with common sense at all, since it does not entail that common sense claims which imply the existence of multiple material objects are false. Such claims can be strictly and literally true, even though the correct ontology does not include a multiplicity of material objects. I don't have the space here to offer a thorough critique of Horgan and Potrc's view, but I will say that I am sceptical that it really manages to reconcile monism with common sense. Sure, it seems in line with common sense to allow that claims such as, "there are tables" are true, but that alignment with common sense soon seems to vanish once it is further asserted that there aren't really any tables. Horgan and Potrc's strategy, I would suggest, seems to give with one hand only to then quickly take away with the other.
} 
It seems only fair to suppose that the same principle should apply to any revisionary metaphysical theory. ${ }^{10}$ If that theory is accompanied by a SAE, then the common sense objection alone should not be considered sufficient grounds for its refutation. If a theory denies the existence of $F \mathrm{~s}$, but comes equipped with an SAE that explains why it seems as though there are $F \mathrm{~s}$, then it is not rationally legitimate to object to the theory by simply saying "but there is an $F$ ". So, of course, the same goes for monism. If the monist can provide an SAE that explains why it seems as though there is a multiplicity of concrete objects when in fact there is not, one can no longer object to monism on the grounds that it is obvious that there are many things. A monistic SAE would nullify the common sense objection. In Sect. 5 I will provide my own SAE for the monist, and thus carry out that nullification. This will not show that monism is true, of course. There may be any number of good reasons to believe it is false. What it will do, however, is show that the common sense objection is not alone sufficient for its rejection. To reject monism, you have to work a bit harder than that.

\section{Pre-empting an objection}

Before I present my proposed SAE for the monist, I first want to pre-empt an objection that I can envisage being levelled at the present strategy. The objection is as follows. If all one needs for a theory to be taken seriously is some kind of SAE, then that opens the door to all sorts of crazy and outlandish theories being taken seriously, despite the fact that they are surely undeserving of any attention. This is because, for an SAE to be sufficient, it merely has to make a theory consistent with the phenomenological data. But one can easily concoct all manner of crazy theories that are merely consistent with the data. Surely that doesn't mean that all those theories deserve to be taken seriously? To illustrate the supposed problem, let me concoct a deliberately absurd example. Consider a theory which I shall call 'teapot monism', and one of its proponents, a teapot monist. The teapot monist, just like the standard monist, believes that monism is true and that there is only a single concrete object in existence-the world itself. In addition to the world, however, the teapot monist also believes that there is an undetectable and omnipotent teapot that exercises total control over the cosmos. ${ }^{11}$ According to this view, the reason it seems as though there is a multiplicity of concrete objects is simply because the teapot makes it so. It is the wont of this omnipotent item of crockery that we are misled into believing that there are many things when there is in fact only one. The teapot is capable of this Cartesian-style deception since it is, as we have already stipulated, omnipotent. Now this explanation, despite being utterly fatuous, constitutes an SAE for the teapot monist, for it makes his theory perfectly consistent with the phenomenological data; if teapot monism were true, our

\footnotetext{
${ }^{10}$ By a "revisionary metaphysical theory", I simply mean any theory of metaphysics that entails the negation of some common sense proposition.

11 To keep this consistent with the central tenet of monism, we must also suppose that the teapot is not concrete.
} 
experiences would remain exactly the same. But surely this doesn't mean we should take the teapot monist seriously? It is surely an absurd view, and so undeserving of our attention that we should dismiss it out of hand.

Well, yes and no. One thing can be agreed upon: teapot monism is an absurd view, and it is certainly not worthy of any consideration (at least, not any prolonged consideration). However, the point I mean to impress here is that despite its absurdity, because it comes equipped with an SAE, one cannot object to it by appeal to the common sense objection. It is not rationally legitimate to say "teapot monism is clearly false, because it conflicts with the obviously apparent fact that there are many things!". Such an objection would not hold any water against the teapot monist, since teapot monism is perfectly consistent with the apparent multiplicity of material things. Regardless of how ludicrous one takes teapot monism to be, one cannot object to it by merely pointing to the appearance of plurality. But, of course, one does not need to object to teapot monism in this way. Indeed, that would be a most peculiar way to object to it. For the most obvious problem with teapot monism is not that it underestimates the number of material objects. Rather, it is that it grossly overestimates the number of omnipotent teapots. The conspicuous absence of any possible argument that could provide even the least compulsion to believe in the postulated teapot is reason enough to dismiss it out of hand. Secondary considerations about the physical ontology that teapot monism posits should never come into it.

However, we should not forget to recognise that in dismissing teapot monism in this way, we are not dismissing it because it conflicts with the ontology of common sense. ${ }^{12}$ Rather, we are dismissing it because its accompanying SAE, that is, the explanation it provides for the phenomenological data, is wildly implausible and completely unmotivated. It is so implausible and so unmotivated, in this particular case, that we can quickly dismiss it out of hand, and maintain that the theory is unworthy of any serious consideration. But this does not change the fact that teapot monism does not succumb to the common sense objection. Ludicrous as it may be, because it provides an SAE, we cannot reject it solely on the grounds that it appears obvious that there are many material things. So in response to the original objection, it must be conceded that the strategy I am proposing does result in the fact that all manner of far-fetched and absurd theories can be easily immunised from the threat of the common sense objection. But this will not mean that we are thereby required to take all of these far-fetched theories seriously, and offer them all their place on the philosophical landscape. For in these far-fetched cases, just as in the case of teapot monism, there will be other reasons which are immediately apparent, and quite sufficient to quickly reject them. What I aim to show in the following sections, however, is that the theory of monism I am concerned with is not far-fetched in the sense just described. For the monist can provide an SAE to explain the appearance of plurality, which is not wildly implausible, and for which there are not any

\footnotetext{
12 I suppose that one could argue that we are dismissing it for precisely that reason, because the ontology of common sense is quite devoid of omnipotent teapots. But this should not affect the argument. The important point is that we are not dismissing teapot monism because it conflicts with the common sense claim that there is a plurality of material objects.
} 
defeating reasons which are immediately and obviously apparent. Therefore monism does deserve, I claim, to be taken seriously.

\section{Explaining the appearances}

I suggest that in order to provide an SAE, and to explain the appearance of plurality, the monist should appeal to the world's properties. To begin with some very broad brushstrokes, the monist should say that the world, as a whole, has certain properties which give rise to the appearance of there being a multiplicity of material things. For instance, if it appears that there is a cat at location $l$, then whilst the monist will deny the cat's existence, she will maintain that the world has a certain property (or set of properties) which give rise to the appearance of there being a cat at $l$. For the monist, we live in a world of properties, not in a world of material things.

But this is very broad. So to make the explanation a little more thorough, and indeed convincing, let me try to add a little depth to the picture; to flesh out in a little more detail exactly how the world's properties can account for the qualitative appearances that we experience. To begin, I think that the monist should appeal to a particular type of property: distributional properties. A distributional property is a property that not only ascribes some quality to an object (e.g. redness or blueness), but that also ascribes the particular way in which that quality is distributed across the extension of that object (e.g. being red and blue striped). Josh Parsons introduced the idea of distributional properties some years ago, and says of them: "a distributional property is like a way of painting, or filling in, a spatially extended object with some property" (2004: 173). Distributional properties are, it seems to me, most intuitive things. We certainly talk as though there are such properties all the time. Consider, for example, the following statements:

1. The zebra is black and white striped

2. The surface of the lake is rippled

3. The Swiss cheese is holey

These are all perfectly ordinary, everyday statements, yet taken at face value they all seem to refer to distributional properties, i.e. the properties of being black and white striped, being rippled, and being holey. These kinds of statement do not, of course, demonstratively prove that there are such things as distributional properties, but they do serve nicely to illustrate what such properties are supposed to be like. The idea of a distributional property is, I would suggest, very easy to grasp.

An important thing to note here is that if distributional properties are to fulfil the explanatory role that the monist requires of them, then they must be taken as being irreducible. What I mean by that is that if some object, o, has some irreducible distributional property, $P$, then $P$ is not reducible to some conjunction or aggregate of non-distributional properties had by $o$ 's parts. This claim is somewhat controversial because the thought that distributional properties are reducible in this sense has at least some prima facie force to it. For instance, one might well concede that a zebra has the property of being black and white striped, but maintain that it only has this property in virtue of its parts having certain non-distributional 
properties, i.e. it has parts which are black and parts which are white, and those parts stand in the appropriate relations to give rise to stripy-ness. ${ }^{13}$ It might be thought, therefore, that the property of being black and white striped simply reduces to a conjunction of these non-distributional properties had by the zebra's parts. To be suitable for the monist's purposes, however, distributional properties cannot be taken to be reducible in the sense just described. The reason for this should be fairly obvious. For if the monistic world is taken to instantiate various distributional properties, then those properties cannot be reduced to some conjunction of nondistributional properties instantiated by the world's parts-because the world has no parts! In order to implement the strategy being proposed, therefore, the monist requires not only distributional properties, but irreducible distributional properties.

I will not be arguing for the existence of irreducible distributional properties here, and that is for a number of reasons. First, I am constrained by space in a paper of this length. Secondly, compelling arguments for their existence have been presented elsewhere. ${ }^{14}$ Thirdly, as I have shown above, distributional properties are really most intuitive, so I will assume that I am not asking too much of the reader by continuing as though there are such things. I will assume that the reader has a perfectly good idea of what I mean when I talk of an object being black and white striped, or being rippled, for example. Fourthly, and finally, the objection that irreducible distributional properties are impossible, or that they are of necessity reducible, would not really threaten the stated goal of this paper. This is because my present aim is to overcome the common sense objection against monism which states that it is obviously false. But it can hardly be said to be common sense that distributional properties are necessarily reducible to conjunctions or aggregates of non-distributional ones. So if one were to object to my defence of monism by presenting arguments against the possibility of irreducible distributional properties, then although those arguments could ultimately undermine my overall project, there is a certain sense in which I would welcome them. ${ }^{15}$ For it would demonstrate that the objector had at least taken monism seriously enough to try and argue against it, rather than simply reject it out of hand for being obviously false. So with that said, it will be a central assumption in what follows that irreducible distributional properties are at the very least possible.

So now the task remains to explain how irreducible distributional properties can come to the monist's rescue; how they can help explain the appearance of plurality despite there being, in reality, only singularity. To do so, I think it is first necessary to make a couple of important distinctions. We ought, I claim, to distinguish distributional properties from what we can call 'distributable properties' on the one hand, and 'distribution patterns' on the other. ${ }^{16}$ Let me start with the former. To put

\footnotetext{
13 More likely, it would be supposed that the colour properties themselves reduce to more fundamental properties, such as the base physical properties of the sub-atomic particles that make up the zebra's skin. But this shouldn't affect the point being made.

14 See Parsons (2000, 2004).

15 And I should state for the record that I am not aware of any arguments that show irreducible distributional properties to be impossible.

16 Parsons (2004) draws the first of these distinctions, and the term 'distributable property' is his.
} 
it simply, albeit somewhat tongue-twistingly, a distributable property is a property that a distributional property distributes. A distribution pattern, on the other hand, refers to the specific way in which a distributable property is distributed across the extension of an object. To give an example, the distributional property being black and white striped, involves the two distributable properties blackness and whiteness, and the distribution pattern stripy-ness. ${ }^{17}$ This distinction seems quite legitimate, since it seems clear that distributable properties and distribution patterns, taken alone, are distinct from distributional properties. After all, an object could instantiate blackness and/or whiteness without instantiating the distributional property being black and white striped, and likewise, an object could instantiate stripy-ness without instantiating being black and white striped. ${ }^{18}$ It seems clear, therefore, that these types of properties should be recognised as being distinct.

With these distinctions in mind, we can now piece together a fairly simple strategy that the monist can employ in order to explain the appearances. To illustrate, let me begin with a simple example. Imagine an extended, yet mereologically simple object that is cube-shaped. ${ }^{19}$ Let's call it 'Cube'. Now also suppose that Cube is multicoloured. More specifically, suppose that Cube is coloured in such a way that it appears something like the object depicted in Fig. 1. Given the way that Cube appears, it would be quite natural for one to describe it by saying things like, "Cube has one face that is red, another face that is blue, another face that is green..." and so on. Or one may say something like, "Cube has six different faces, each of which is a different colour".

Now in light of this, it would also be fairly natural for one to suppose that Cube has different parts (i.e. faces), each of which instantiates a different property (i.e. colour). After all, the word 'face' is being employed as a noun-a singularly referring term - so there must be some thing, some object, to which it refers, or so it would be natural to think. But this supposition would be wrong, of course, because Cube is, ex hypothesi, mereologically simple. It has no parts, thus there are no things to which we refer when we talk of Cube's 'faces'. Now this may seem to create some sort of tension. For what are we talking about when we say "Cube has one blue face and one red face..." and so on, if Cube has no faces? We are surely not talking nonsense? We are surely not hallucinating? This tension can easily be resolved if one endorses irreducible distributional properties. One can maintain that Cube has no parts (it has no faces), but rather, that it instantiates a six irreducible distributional properties. Each distributional property will involve a particular distributable property (e.g. blueness or greenness etc.) and a particular distribution pattern. The distribution pattern will be such that it is as if Cube has a face which is

\footnotetext{
17 The term 'stripy-ness' is, of course, somewhat vague. To specify the precise distribution pattern would be more difficult, and would probably involve a long chain of spatial co-ordinates.

18 It is an open question, however, as to whether an object could instantiate a distributable property (like blackness) without also instantiating any distribution pattern. In my view, this would be impossible, but I will not pursue this question any further here.

19 It has been suggested to me that it may not be that easy to imagine an object that is both extended and mereologically simple. In what follows I will ignore these concerns, however, and suppose that extended simples are at least conceptually possible.
} 
Fig. 1 Cube

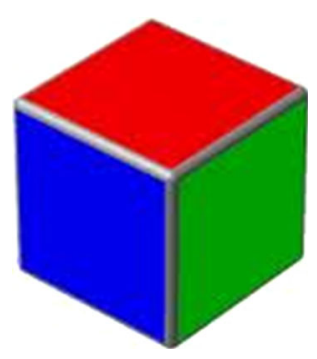

blue or green, i.e. the blueness will be distributed across that region of space which corresponds to the location of Cube's alleged blue face and the greenness will be distributed across that region of space which corresponds to the location of Cube's alleged green face. Cube's other distributional properties will be similar, but they will involve different distributable properties (i.e. different colour properties), and different distribution patterns (i.e. they will distribute the distributable properties across those regions which correspond with the location of Cube's other alleged faces). ${ }^{20}$ These irreducible distributional properties explain how it is that Cube appears as it does, despite the fact that it has no parts.

The initial tension, therefore, is resolved, as it can be explained as resulting from a mis-characterisation of the phenomenological facts. We can describe the qualitative variation that Cube exhibits by either talking of its different coloured faces, or by talking about its distributional properties. The former way characterises Cube pluralistically, as a composite object made of different parts that each exhibit different properties, whereas the latter characterises Cube monistically, as a mereologically simple object that instantiates certain irreducible distributional properties. In this case, we have stipulated that Cube is mereologically simple, thus it would be the latter description that gives the most accurate characterisation. If, however, Cube were composite, then the former description would be more accurate.

If this explanation is accepted, then it only takes a short leap of the imagination to see how it can also be applied to much larger, and more complex objects, like the actual world. The world exhibits vast and diverse qualitative variation. We naturally describe this variation by supposing it consists of many different objects, each of which exhibits different qualities. But, of course, the same appearances could be explained by positing distributional properties. The world as a whole instantiates various qualities (distributable properties), and they are distributed across the world's extension in particular ways (distribution patterns). So if it appears that there is a plurality of material objects like tables and chairs, cats and dogs, and so on, then the monist can explain these appearances by saying that the world

\footnotetext{
${ }^{20}$ Alternatively, one could perhaps say that Cube instantiates a single distributional property (we could call it a 'complex' distributional property) that involves six distinct distributable properties, and six distinct distribution patterns. It is an interesting question as to which of these options would be preferable, but it is not a question I will consider here.
} 
instantiates certain properties (i.e. table-ness, chair-ness, cat-hood, etc.) distributed in patterns that correspond with the locations of the alleged entities in question.

Of course, when sketching out a picture of what reality is truly like, it is unlikely that the monist will want to appeal to properties like table-ness or cat-hood. But she does not have to. Indeed, very few metaphysical theories, pluralistic or otherwise, will refer to ordinary macroscopic objects and properties when describing what reality is like at the most fundamental level. This is just in the same way that our best current scientific theories will make no mention of ordinary macroscopic objects like tables or cats, or ordinary properties like colour or taste. In fact, the monist is free to apply her explanatory strategy to those very scientific theories. Let us suppose, for instance, that the ultimate scientific facts (i.e. those that constitute our best current scientific theories) involve sub-atomic particles (like leptons and quarks) instantiating certain fundamental properties (like mass and charge). Just as she did with Cube, the monist can then translate these facts into facts about the world and its distributional properties. Firstly, she will take the fundamental properties posited by science (i.e. mass, charge, etc.) as the world's fundamental distributable properties. Then she will insist that rather than being instantiated by sub-world objects (like sub-atomic particles) they are instantiated by the entire world, in certain distribution patterns. These distribution patterns will correspond to the distribution of the alleged sub-world objects.

Perhaps the ultimate scientific facts will be cast in very different terms than those I have suggested? One thing is for sure, they are likely to be very complex. But I do not pretend for a minute to know what the ultimate facts of science are-I am not a scientist after all. But I don't think that is too important, for it is the principle of the strategy that is the key thing. The monist has a general strategy for translating facts cast in pluralist terms into monist-friendly facts cast in terms of the world and its distributional properties. Take any fact that involves an alleged sub-world object having some property or other. Such a fact will have the general form, ' $a$ is $F$ '. The monist will not accept this as a genuine fact (because, of course, there are no subworld objects-there is no referent of $a$ ), but will accept that it at least gets something right about the qualitative nature of the world. (Just in the same way that saying "Cube has a green face" gets something right about the qualitative nature of Cube, albeit in a somewhat misleading way). She will maintain, however, that it is more accurately expressed in terms of the world instantiating a particular irreducible distributional property. The distributable property involved will be F-ness, and the distribution pattern will be such that it corresponds with the alleged location of $a$. I.e. the distribution of F-ness will overlap that, and only that, particular location. Once it is recognised that the monist has this strategy available, it should also be recognised that it doesn't matter what the alleged sub-world objects are purported to be (i.e. faces of a cube, sub-atomic particles, tables, cats, or whatever), or what the properties ascribed to them are (colours, mass, charge, or whatever). It is the principle that is important. And if the principle is accepted, and I see no reason why it should not be, then it provides the monist with a satisfying way of explaining the appearances. The world and its irreducible distributional properties are quite sufficient to explain the appearance of plurality. 


\section{Objections}

There are some potential problems with the explanation I have just given, so let me try and address some of them here. First, one may be worried that the descriptions of the distribution patterns I am invoking are somewhat vague. For it may well be claimed that I have not said very much about what these distribution patterns are really like. Rather, I have simply said that distributional properties involve certain distribution patterns which distribute the appropriate distributable properties in the appropriate ways. But this is all rather imprecise, is it not? Moreover, one might worry that any attempt we can make to give a more precise description of these distribution patterns will necessarily involve pluralistic language, i.e. talk of 'alleged objects' and/or 'regions of space'. For instance, in the example involving Cube, I described the distributional properties it supposedly has by saying things like: they distribute the blueness across that region of space which corresponds to the location of Cube's alleged blue face. But, of course, Cube doesn't have any faces. Moreover, the reference to regions of space looks particularly suspicious, because it is unlikely that the monist will want to allow that there are any such things as spatial regions. But in that case, what sense can we really make of these descriptions? Moreover, if the use of such pluralistic language is unavoidable in our descriptions of distribution patterns, then one might think that the corresponding pluralistic posits (e.g. faces of a cube, and/or regions of space) are indispensable to our explanations of them. And if they are indispensable to our explanations, then we have good reason to believe that they exist, or so one might reasonably think.

In order to allay such concerns, my response would be that these distribution patterns are merely hard to describe, not hard to understand. It is very hard for us to describe Cube's purported distribution patterns. Or, at least, it is hard for us to describe them in terminology that is not overtly pluralistic. We may need to talk of Cube's 'faces', for instance, or the regions of space that correspond with those faces. But this is, I repeat, merely a problem with description. It is a linguistic problem, not an ontological one. For it is not difficult to conceive of an object like Cube, and it is not difficult to understand what the distribution patterns making up Cube's distributional properties must be like in order for it to look as it does. The mere fact that we can't accurately describe Cube's distributional properties in English without a misleadingly pluralistic slant should not cloud our understanding of what these properties are like, and neither should it force us into believing that Cube is mereologically complex. I am inclined to believe that the difficulties involved in describing these distributional properties should serve only to remind us of the descriptive limitations of our language, rather than tell us anything about what the object being described is really like. Indeed, if the descriptive powers of language are taken to put such heavy restrictions on our ontological conclusions, then monism would never have even got off the ground.

A second concern one might have is that my explanation seems to involve a radical and implausible scepticism about the veracity of our perceptions. For it may well be thought to be perceptually apparent that there is a multiplicity of material objects. That is, it is perceptually apparent there are tables and chairs, doughnuts 
and pillar boxes, and so on. But if my explanation is right, it turns out that these perceptual platitudes are in fact not platitudes at all, but falsehoods; it turns out that our perceptual apparatus is systematically, and grossly, deceiving us about the true nature of the world. But such a scepticism is wildly implausible, or so one might think. Sure, it would be foolish to think that we never get anything wrong about the way the world is, but the sheer magnitude of this error is surely so great as to render it entirely implausible, or so the objector might say. ${ }^{21}$

One way to respond to this objection would be to simply bite the bullet and admit that if you want to be a monist, you must also be a radical sceptic. But I think this would be to concede too much. In fact I don't think the monist has to accept these charges of scepticism at all. Or perhaps more modestly, I think that the kind of scepticism the monist does have to accept is no way near as radical as the objection seems to imply. The way the objection is set out seems to imply that if monism is true, then the world we perceive is nothing more than an illusion; that the ordinary objects like doughnuts or pillar boxes that we think we perceive are mere figments of the imagination. When we think we perceive a table or a cat, for example, then on this view, we are no better off than a weary traveller stranded in the desert who thinks he perceives an oasis in the distance, or someone under the influence of hallucinogenic drugs who thinks that he is crawling with bugs. But this is to wildly over-exaggerate the type of deception that is going on. Hallucinations or mirages $d o$ involve a radical deception of the senses. They involve us conjuring in the mind some qualitative feature of the world that in reality is not there. The objects of hallucinations are pure inventions of the mind; inventions that bear no correlation whatsoever to external reality. But this is a totally different, and far more radical, type of deception to that which is involved if it turns out that the world is monistic.

If it turned out that monism was true, and the world was not in fact a plurality of distinct material objects, but a single mereologically simple object that instantiated various irreducible distributional properties, then it would not be right to say that the tables and chairs and doughnuts and pillar boxes and so on, that we think we perceive, are pure inventions of the mind; figments of the imagination that bear no correlation to external reality. When we perceive what we think is a table, for example, we would not be mentally manufacturing some qualitative feature of the world that did not in fact exist. Rather, we would be perceiving the world as it really is, but merely mischaracterising it. If monism were true, we would not be guilty of gross errors of perception; we would not be victims of some nefarious deceit on the part of our senses. Rather, we would be merely guilty of an error of interpretation. We would be perceiving the world as it really is, accurately taking in its rich and diverse qualitative variation, but we would be misinterpreting those perceptions. We would be guilty of mischaracterising the perceptual data pluralistically, when a correct characterisation would be monistic.

\footnotetext{
21 This objection is similar in many ways to the common sense objection that is the main concern of this paper. But it is not the same. The common sense objection says that monism is inconsistent with the appearances. This objection allows that monism is consistent with the appearances, but maintains that that consistency comes at a cost: a radical scepticism about our perceptions.
} 
As an analogy, suppose that Peter van Inwagen's view was true, and the only material objects in existence were microscopic simples and living organisms. In that scenario, when you thought you were perceiving a table, for instance, you would be wrong, you would in fact only be perceiving a collection of microscopic simples arranged in tabular form. But it would be misleading to say that you were hallucinating; to say that you were seeing things that were not there. A more truthful account would say that you are perceiving the world as it really is, but misinterpreting the perceptual data. You would be mistakenly supposing that the particles in front of you composed a whole, when they did not. And the same is the case if monism were true. We would be perceiving the world as it really is, but we would be mistakenly supposing that it decomposes into multiple objects when it does not. Thus where we see a certain distribution of green-ness, for instance, we say we have seen a green object. This green object is not a figment of the imagination, but a product of our mischaracterisation of the phenomenological data.

Thus, the sort of mistake we are making if monism is true is not akin to the kind of mistake someone makes when they see a mirage in the desert, or when they hallucinate under the influence of drugs. It would be more akin to the kind of mistake we make when we see a circular object as being elliptical when at an angle, or when we see something as being very small when in fact it is merely far away. In these sorts of cases, we are perceiving the world as it really is, but the way that we interpret those perceptions can lead us to forming misleading or inaccurate beliefs about the nature of the world. The same sort of thing would be going on, I claim, if monism were true. So there is a sense in which monism does entail a scepticism about the veracity of our perceptions. But it is not a radical scepticism, and it is no way near as much of a cost as the objector would have us believe.

Of course, the question remains as to why we make this interpretive error. This is a difficult question, but I have my suspicions as to what the answer to it is. I suspect that the source of our pluralistic misinterpretation is language. Quine once said that "our language shows a tiresome bias in its treatment of time" (1960: 170). His point was that because our language contains all manner of tensed variants of verbs, it often leads us to presume that reality really is tensed when in fact (as far as Quine was concerned at least), it is not. I will remain neutral here about whether Quine was right or not about the reality of tense, but I think he was right in making the more general point that certain central features of our language often lead us to presume that there are corresponding features in reality, when there may not, in fact, be any such features at all. In this respect I think our language shows a number of tiresome biases in its treatment of all manner of things. But it shows no greater bias, I claim, than in its treatment of multiplicity.

Our language is inherently pluralistic. ${ }^{22}$ It comes replete with a vast stock of nouns, each of which purports to pick out some thing; some object among many. Sentences are, in the vast majority of cases, structured in a subject-predicate form, whereby the subject is taken to be some object or other, and the predicate taken to

\footnotetext{
${ }^{22}$ When I talk of 'our language' I mean English, but I think that what I say will apply to most natural languages.
} 
refer to some characteristic of that object. Indeed the predication of such subjects often serves precisely to distinguish them from other subjects. But implicit in all this, of course, is the fact that there is a multiplicity of objects in the first place. Nothing about this is particularly revelatory-it is just the way our language works. But given that the way we communicate is so inherently pluralistic, it is really quite unsurprising that the way we think is so inherently pluralistic too. Language plays such a central role in our lives that it is quite ingrained in the way we think and the way we act; it is entirely second nature to us. Thus, again, it is unsurprising that the pluralistic picture of the world that our language paints is also ingrained in the way we think and act. The very structure of our language, a system which is so fundamental to our way of life, guides us inexorably towards pluralism.

The obvious line of response to these thoughts would be to say that our language is inherently pluralistic precisely because the world is also pluralistic. In other words, our language paints a pluralistic picture of the world and it paints accurately. But whilst this response might be reasonable, it certainly doesn't constitute a proof. Quine would surely have been unimpressed, for instance, if someone had objected: "but language is tensed, therefore reality must be too". The whole point of the thought being expressed is that the nature of language may mislead us into taking a mistaken view of the world.

Of course, a further question still remains, of why language developed as it did. That is, why did we develop a language so inherently pluralistic if the world which we use it to describe is really monistic? I can't, of course, give a definitive answer to such a difficult question, but I can suggest some plausible candidates. Perhaps pluralistic languages such as English are just very effective means of communication? After all, it is beyond doubt that we do communicate very successfully. Perhaps we are simply hard-wired to think pluralistically, and this innate feature of human cognition is reflected in our language? Perhaps there is some evolutionary reason for why language has developed as it has? All of these explanations are perfectly plausible, I would suggest, and that is regardless of whether the world actually is pluralistic or monistic. Which of these explanations-if any-is right, however, is another question entirely. But hopefully the main point should be clear: it is not unreasonable to suggest that our language could have developed in such a way that it grossly misrepresents the true nature of reality, and this could be the case regarding the reality (or not) of tense, or the world's mereological structure, or any number of (alleged) features of the world. Therefore, if our philosophical reasoning leads us to a conclusion that is at odds with the picture of the world painted by ordinary language then we should accept that the error could just as well lie on the linguistic side of things as it could in our reasoning.

It is very hard for us to even conceive of a way of describing a monistic world that is not pluralistic. At least, it is certainly very hard to see how we could describe such a world in a perspicuous manner, in English, that did not employ nouns that purport to refer to sub-world objects or parts/regions of the world. Perhaps other types of languages are possible that would be perfectly suited to the job? If so, then I can only think that they would be very far removed from the ordinary languages we 
actually employ. ${ }^{23}$ I won't be attempting to come up with such a language here, although that could be an interesting project. But whether such a language could be produced is really beside the point. If it turns out that a monistic world is difficult to describe (in English or any language), then that should have no bearing on whether such a world is possible. It simply means that it is hard for us to describe. Quantum Field Theory is quite difficult to explain, but that doesn't make it any less likely to be true.

\section{Concluding remarks}

I have hopefully shown that the common sense objection against monism is not really a serious objection at all. By appealing to irreducible distributional properties, the monist has a straightforward way of explaining how the world appears as it does, despite having no parts. In light of this, it would be little short of naive to object to monism on the sole grounds that it is perceptually obvious that the world has parts. Of course, I suspect that most of those who wield the common sense objection against monism are well aware that it is a naive, indeed flippant, way to respond to a serious theory of metaphysics. After all, many metaphysical theses conflict with common sense. Mereological Nihilism, for instance, denies the existence of all composite objects just like monism does, yet it is a respected metaphysical theory that is currently growing in popularity. It would not do for someone to object to nihilism solely on the grounds that it is obviously false. And the same goes for many other theories. But for some reason, monism has slipped through the net. For some reason, it is deemed acceptable to object to monism with little more than a gesture to the appearance of plurality. This is a gross inconsistency, which it is the purpose of this paper to expose. Monism is a serious and respectable metaphysical theory, with a rich historical pedigree. It deserves to be taken seriously.

As a final note, I should stress that just because one should take monism seriously does not mean one must accept it is true. There are all sorts of independent objections that one could raise against it and, moreover, there are a number of ways in which the explanation I have just proposed could be objected to. One might think that distributional properties are necessarily reducible, for instance. One might have independent reasons to suppose that extended simples are impossible, or at least, that qualitatively heterogeneous extended simples are impossible. Alternatively, one might think that a more rigorous translation method is required for recasting pluralist statements into monistic statements involving distributional properties. One might even think that there are certain pluralistic statements which the monist is incapable of accounting for by appeal to distributional properties. These are all serious avenues of response and, indeed, I can admit that more work is probably

\footnotetext{
${ }^{23}$ Hawthorne and Cortens (1995) attempt to flesh out such a language by replacing talk of objects with suitable adverbs. E.g. "there is a white pebble" would be translated as "it is pebbling whitely there". I think that their attempt is most admirable, but it only serves to reinforce the point: a language that doesn't refer to multiple objects is going to be far-removed from the languages with which we are ordinarily acquainted.
} 
required on all of these fronts in order to make monism a more robust theory. But the important point is that none of these objections are common sense objections. I would welcome it if a flurry of philosophical research were to focus on these types of objection and their possible solutions. Indeed, that is one of the very goals of this paper.

Open Access This article is distributed under the terms of the Creative Commons Attribution 4.0 International License (http://creativecommons.org/licenses/by/4.0/), which permits unrestricted use, distribution, and reproduction in any medium, provided you give appropriate credit to the original author(s) and the source, provide a link to the Creative Commons license, and indicate if changes were made.

\section{References}

Barnes, J. (1979). Parmenides and the eleatic one. Archiv fur Geschichte der Philosophie, 61, 1-21.

Cornell, D. M. (2013). Monism and statespace: A reply to Sider. Analysis, 73(2), 230-236.

Goff, P. (2012). There is more than one thing. In P. Goff (Ed.), Spinoza on monism (pp. 113-122).

Basingstoke: Palgrave MacMillan.

Hawthorne, J., \& Cortens, A. (1995). Towards ontological nihilism. Philosophical Studies, 79, 143-165.

Hocking, W. (1929). Types of philosophy. New York: Scribner Press.

Hoffman, J., \& Rosenkrantz, G. S. (1997). Substance: Its nature and existence. London: Routledge.

Horgan, T., \& Potrc, M. (2000). Blobjectivism and indirect correspondence. Facta Philosophica, 2, 249-270.

Horgan, T., \& Potrc, M. (2008). Austere realism. London: MIT Press.

Parsons, J. (2000). Must a four-dimensionalist believe in temporal parts? The Monist, 83(3), 399-418.

Parsons, J. (2004). Distributional properties. In F. Jackson \& G. Priest (Eds.), Lewisian themes: The philosophy of David K. Lewis (pp. 173-180). Oxford: OUP.

Quine, W. V. (1960). Word and object. Cambridge, MA: MIT Press).

Rea, M. (2001). How to be an eleatic monist. Philosophical Perspectives, 15, 129-152.

Russell, B. (1918). The philosophy of logical atomism. In D. Pears (Ed.), The philosophy of logical atomism (pp. 1-125). La Salle: Open Court.

Schaffer, J. (2007). From nihilism to monism. Australasian Journal of Philosophy, 85(2), 175-191.

Schaffer, J. (2010). The least discerning and most promiscuous truthmaker. Philosophical Quarterly, 60(239), 307-324.

Sider, T. (2007). Against monism. Analysis, 67(1), 1-7.

Van Inwagen, P. (1990). Material beings. Ithaca: Cornell UP. 